dominates the whole position. The masts on the Alexandra palace will probably be about $600 \mathrm{ft}$. above sea-level, and there are few local obstructions. In the London area, it is understood that a wavelength of $6 \cdot 6 \mathrm{~m}$. will be employed for the visual and $7 \cdot 2 \mathrm{~m}$. for the sound broadcasts. As these rays are propagated in practically straight lines, their range does not extend much further than the visual horizon. The London area will be roughly a circle of radius 30 miles. There are some outstanding financial problems that have to be settled, such as the relative values of the televising and broadcasting rights of a prize fight. In the cinema industry, coloured pictures have greatly improved, so that it only needs stereoscopic projection to perfect them.

\section{Effects of the 1934 Drought in the United States}

IT was only to be expected that the American drought of 1934 would extend well into the growing season of 1935, in some parts of its extensive area, and this is proving to be the case. In a number of articles that have been issued by Science Service, Washington, D.C., during the past few months, the gradual contraction of the stricken area has been traced. In one such article, dated March 13, early spring rains in the Plains were mentioned, and a great excess from the Ohio Valley to the Gulf, sufficient to delay spring ploughing. On March 27 light rains were described as having eased the situation in the northern part of the western drought area ; but dust storms were reported in the completely dry region in eastern Colorado and western Kansas and in Texas. On April 20 an improvement was noted in Texas and Oklahoma, and a hope on the part of the forecasters in the Weather Bureau that western Kansas and eastern Colorado might soon be relieved by invading depressions. Articles dated May 1 and 2 showed that this hope had not been fulfilled, the area in question remaining to represent the temporary "Great American Desert". A faint sprinkle of rain was described as having evaporated as fast as it fell in Dodge City. In the relieved areas, the cold weather and sodden fields, and the resultant delay in farming work, were said to be accepted with complacency after the previous extremes of drought and heat.

DUST storms, leading to the loss of the cultivated surface soil, had become a commonplace occurrence in the United States before the drought had nearly reached its greatest extent, causing great inconvenience and material damage to the States lying to the eastward of the driest region, as well as to western farmers. The drought itself is held, however, to be only partly responsible, as the dry soil would not have been blown away had the Plains not largely been deprived of their former permanent grass covering, of which the roots would have bound the soil in place through even the worst periods of deficient rainfall. Another article describes one of the processes whereby the drift of loose soil has been to some extent countered. This process, known to farmers as 'listing', consists of specially deep ploughing with the aid of motor-driven tractors. A special plough is used, which throws the soil on both sides; the furrows may be as many as fifteen feet apart, and are driven at right angles to the prevailing winds, which are generally from the north-west. Where the soil is heavy the tops of the ridges are covered with something more coherent than the normal surface tilth, and this partly accounts for the efficacy of the method, which, however, is due mainly to the fact that as the loose soil begins to move under the action of the wind, it tends to fall into the furrows and to be trapped in them. It is stated that the Soil Erosion Service does not regard this 'listing' as a solution of the problem of wind-erosion, the real solution being to restore the permanent grass, much of which was ploughed up during the War so that cereals could be grown.

\section{List of British Vetebrates}

FEw naturalists have at hand complete lists of the various groups of British vertebrata, and yet in the absence of such lists reference and checking often become unutterably tedious. The suggestion of the Association of British Zoologists that a complete check list of all British vertebrates should be compiled was, therefore, a sound proposal, and the list as it now appears will prove of value in many ways, especially to workers of wide interests. This is clearly due to the way in which the British Museum (Natural History) has applied itself to carrying out the suggestion, for apart from the Bird list (by B. W. Tucker) the work of compilation has fallen upon the Museum staff, and for the editing and publication it also has been responsible (pp. 66, price 1s.). The list is a check list and no more, giving the Latin and English names of species and often indicating by letter symbols something about the status. In contrasting this check list with the lists of other countries, one's first impression is that it is a short list, representing a land fauna not outstandingly rich in variety, and a second strong impression is that, much less than other countries, Britain has been subjected to the successful introduction of foreign animals. To the short list of animals marked as introduced should be added, amongst the mammals, the rabbit, the black rat and the brown rat, and the Japanese deer, Cervus sika, which is very much at home in part of the western highlands of Scotland and was introduced so long ago as 1887; amongst the birds, several species of pheasant, for Phiasianus colchicus is now a rare species in the coverts, its place having been usurped mainly by $P$. torquatus.

\section{Traffic-actuated Road Signals}

IN a paper read before the Institution of Railway Signal Engineers by F. Edwards, an abstract of which appears in Roads and Road Construction for July 1, the development of systems of road signalling is described. There are two main developments which may be regarded as milestones in the progress of street traffic signalling. The first system is timecontrolled and, thanks to the specification issued by the British Standards Institution, it works fairly well. Up to the end of February of this year, grants had been issued for the erection of signals at more than 
1,700 crossings in Britain, and naturally the installation of all these crossings is costly. The second step in advance was the introduction of the vehicleactuated method of control, which has several advantages over the time-controlled system. With the time-controlled apparatus the 'right of way' is given to each of two or more intersecting roads for definite periods of time in sequence, quite regardless of the relative volume of traffic on the roads at any particular moment. One of the essentials of any form of control is to keep traffic moving, and this should only be subordinate to safety. The timecontrolled system is powerless to differentiate between the volumes of the flow of traffic in the various directions. Many attempts were made in the past to produce a system which would provide maximum traffic facilities with maximum safety. There are now two systems of vehicle-activated control in practice, called the electromatic and the autoflex respectively. In the former, a vehicle passing over a pad makes contact and completes an electric circuit; in the latter the air in a channel in a rubber moulding is compressed and the compressed air produces the contact. The problem of co-ordinating a series of crossings is now being satisfactorily solved. Oxford Street, London, from Marble Arch to Tottenham Court Road is a good example of the advantages of this kind of control.

\section{Invention of the Venturi Meter}

Is connexion with an article on "Early Hydraulic Engineering", in which the work of Clemens Herschel (1842-1930) is referred to, Engineering in its issue for August 2 reproduces a letter from Herschel to the late Dr. Unwin describing his invention of the Venturi Meter. The letter is dated June 5, 1888, and addressed from the hydraulic engineer's office of the Holyoke Water Power Co., Mass. In his letter, Herschel says he tested a one-inch Venturi Meter, under $210 \mathrm{ft}$. head: "I am now satisfied that here is a new and pregnant principle to be applied to the art of gauging fluids, inclusive of fluids such as com. pressed air, illuminating or fuel gases, steam, etc. Further, that the shape of the meter should be trumpet-shaped in both directions; such a meter will measure volumes flowing in either direction, which in certain localities becomes a useful attribute. ... And we are but in the beginning of the art of measuring pressures, and differences of pressure. When these shall be delicately measured, the Venturi Meter will have become as delicate in its lower limits of capacity, as any other and it is on this score alone, that it is as yet inferior to some of the volumetric meters." The letter was found among the papers placed at the disposal of the Unwin Memorial Committee by Miss Unwin.

\section{Electric Welding in Industry}

THE American Welding Society has awarded the S. W. Miller Medal to J. C. Lincoln, the founder of the Lincoln Electric Company, as the first to apply the electrical are to building construction, and for his improvements in the art of are welding. Mr.
Lincoln has pointed out that by are welding the cost of the repairs of machines has been greatly reduced. It has eliminated the noise of the riveting hammer in building construction. A joint made by are welding is often stronger than the parent metal; while a joint made by riveting never is. The amount of the material needed for the structure is therefore considerably reduced. It is of particular importance in marine construction, where the smooth outline rendered possible by welding appreciably increases the speed of the ship. The most widely used application of all is the replacement of steel and iron castings by welded structural steel. This application gives a method of having a lighter, stronger and cheaper material than it is possible to get by casting. Already about one and a half million tons of castings a year have been eliminated by this method. Mr. Lincoln thinks that welding will entirely eliminate the rivet as a method of joining structures. It will also largely increase the value of worn and broken parts.

\section{Industrial Physicists}

THE Review of Scientific Instruments reproduces in its issue of February the conclusions of the Conference held in New York to consider "the place of physics in industry and the best methods by which that place can be fully occupied". The Conference demands a training which shall develop : (1) a broad knowledge of the principles of physics with a leaning towards classical physics; (2) an intimate working knowledge of the more elementary branches of mathematics; (3) a grounding in the principles of chemistry sufficient for physical research; (4) power of expression in technical and especially non-technical language; (5) realisation that a research worker in industry is justified only by his value to the industry. It would be of great interest to discover whether these are the demands of industry in Great Britain, and if so, whether the training required is being provided by our educational methods.

\section{Institute of Plant Industry, U.S.S.R.}

A uIst of the publications during 1933 of the Institute of Plant Industry, Leningrad, compiled by Strumillo, appears as Bibliographical Contributions No. 4 of the Institute. The list of publications of this Institute, and of the old Bureau of Applied Botany which preceded it, is thus now complete from 1908 to the end of 1933. It covers 57 publications, is pub. lished in Russian and English, and the titles of all contributions of every volume are given in English even in cases where the originals contain no English summary. Most of the Institute's publications of specialised character have English summaries; those publications in this list which are not provided with one are indicated. The Bulletin of Applied Botany, of Genetics and Plant Breeding, together with its supplements, occupies the major portion of this list. The remainder is occupied by non-serial publications and by publications originating from the Institute, but issued by other publishers. "Plant Industry in the U.S.S.R." and "Agricultural Turkey" are two important contributions in the latter category. 